\title{
The Black-White Paradox in Health: Flourishing in the Face of Social Inequality and Discrimination
}

\author{
Corey L. M. Keyes \\ Emory University
}

\begin{abstract}
This paper reviews published research and presents new analyses from the 1995 nationally representative sample from the Midlife in the United States (MIDUS) study to investigate whether there is support for the paradox of race and health in the United States. Findings reveal that Blacks have lower rates of several common mental disorders, but Blacks also have higher rates of flourishing than Whites. Blacks are mentally resilient in the face of greater social inequality and exposure to discrimination as well as high rates of physical morbidity - all of which are distinctive risk factors for mental distress and mental illness in the general population. Findings also show that controlling for perceived discrimination increases the Black advantage in 12 of the 13 signs of flourishing, suggesting that Blacks would have even better mental health were it not for discrimination. This paper concludes by considering what mechanisms - both adaptive and maladaptive - might explain this particular example of resilience in the Black population.
\end{abstract}

In this paper, I review published research and present new analyses from the 1995 nationally representative sample from the Midlife in the United States (MIDUS) study to investigate whether there is support for the paradox of race and health in the United States. This paradox refers to health differentials between Blacks (nonHispanic) and Whites (non-Hispanic) in physical and mental health (Williams \& Earl, 2007). Because of exposure to greater levels of social inequality (e.g., low educational attainment) and discrimina-

This research was supported by membership in the John D. and Catherine T. MacArthur Foundation Research Network on Successful Midlife Development (Director, Dr. Orville Gilbert Brim).

Correspondence concerning this article should be addressed to Corey L. M. Keyes, Emory University Room 225 Tarbutton Hall, 1555 Dickey Drive, Atlanta, GA 30322. E-mail: corey.keyes@emory.edu.

Journal of Personality 77:6, December 2009

(C) 2009, Copyright the Authors

Journal compilation (C) 2009 by Wiley Periodicals, Inc.

DOI: $10.1111 / \mathrm{j} .1467-6494.2009 .00597 . x$ 
tion, Blacks are expected to have worse physical and mental health outcomes than Whites. Although Blacks have greater physical morbidity than Whites, studies indicate that Blacks have lower rates of any mood, any anxiety, and any substance abuse disorders (Kessler et al., 1994; Williams \& Harris-Reid, 1999). Compared to Whites, Blacks sometimes report equal (Dunlop, Song, Lyons, Manheim, \& Chang, 2003) and sometimes lower rates (Breslau, Su, Kendler, Aguilar-Gaxiola, \& Kessler, 2005; Riolo, Nguyen, Greden, \& King, 2005; Williams et al., 2007) of lifetime major depressive disorder, especially after controlling for socioeconomic disparities. ${ }^{1}$

However, mental health is more than the absence of mental illness (Keyes, 2002). Yet even when assessed by a subset of the signs of overall (flourishing) mental health (Ryff, Keyes, \& Hughes, 2003) or the diagnosis of mental health as a complete state- the absence of mental disorders and the presence of flourishing (Keyes, 2007) Blacks have better mental health than Whites. In short, the BlackWhite paradox of health is the beginning of a story about the resilience of the Black population in the face of a common adversity to this population-discrimination and inequality. Although this discrimination and inequality shortens their lives and creates more physical disease and disability during that lifetime, Blacks nonetheless have better overall mental health. This paper concludes by considering what mechanisms might explain this particular source of resilience in the Black population.

\section{Resilience in the Face of Inequality and Discrimination}

The years of research that preceded the study of resilience led to a growing consensus on risk factors for specific psychopathologies that include attributes such as poor social skills, exposure to violence, poor educational outcomes, and persistent poverty (Mrazek \& Haggerty, 1994). Individuals who possess, are exposed to, or reside in known risk factors for a sufficient period of time are said to be "at risk" for negative outcomes. Repeatedly, research demonstrated that at-risk individuals were more likely to develop undesirable developmental outcomes than individuals without or not exposed

${ }^{1}$ Dunlop et al. (2003) did find that Blacks had a higher rate of lifetime dysthymia than Whites, and Breslau et al. (2005) found that although Blacks had lower rates of major depressive disorders (MDD) than Whites, Blacks' MDD was more chronic or persistent. 
to the risk factor. However, not all individuals at risk develop psychopathologies. In fact, enough individuals exposed sometimes to substantial or extreme adversities (e.g., physical trauma) developed normatively and even sometimes developed exceptionally. Resilience, according to Masten and Coatsworth (1998), is a pattern of behavior and functioning indicative of positive adaptation in the context of significant risk or adversity.

The study of risk and resilience seeks to illuminate the causes, mechanisms, and subsequent developmental consequences of constancy (i.e., normative outcomes or "doing okay") and change (namely, recovery from episode of negative change or growth and improvement) in behavior and functioning in the face of adversity. Resilience is therefore a risk factor that has been averted or mitigated or to which individuals have adapted or from which individuals have recovered. The focus of this paper is on the sociodemographic characteristic and social identity of race (or ethnicity), which is a risk because it is a cause of social inequality and exposure to discrimination.

Race/ethnicity (hereafter referred to only as "race") has been linked to increased risk of chronic physical health conditions and premature mortality. Black (non-Hispanic) males and females have high rates of physical disease and lower life expectancies than White (non-Hispanic) males and females (Levine et al., 2001). Sociologists who focus on the effects of inequality invariably argue that disadvantaged populations will suffer worse health outcomes (House, Kessler, \& Herzog, 1990; Link \& Phelan, 1995, 2002; Mirowsky \& Ross, 2003). Thus, racial disparities in physical morbidity support the sociological theory of inequality and poor health outcomes. This has led most researchers to predict that Blacks will suffer higher rates of mental disorder than Whites. However, a growing body of research suggests that Blacks have better mental health than Whites, which presents something of a paradox (Keyes, 2007).

Figure 1 presents the unadjusted prevalence of any of four ${ }^{2}$ mental disorders during the past year by the measure of positive mental health, which includes the categories of languishing (i.e., the absence

\footnotetext{
${ }^{2}$ Using the Composite International Diagnostic Interview (short form), four mental disorders were measured in the past 12 months, including major depressive episode, panic disorder, generalized anxiety, and alcohol dependence. This figure reports whether a respondents had any of these four mental disorders during the past year.
} 


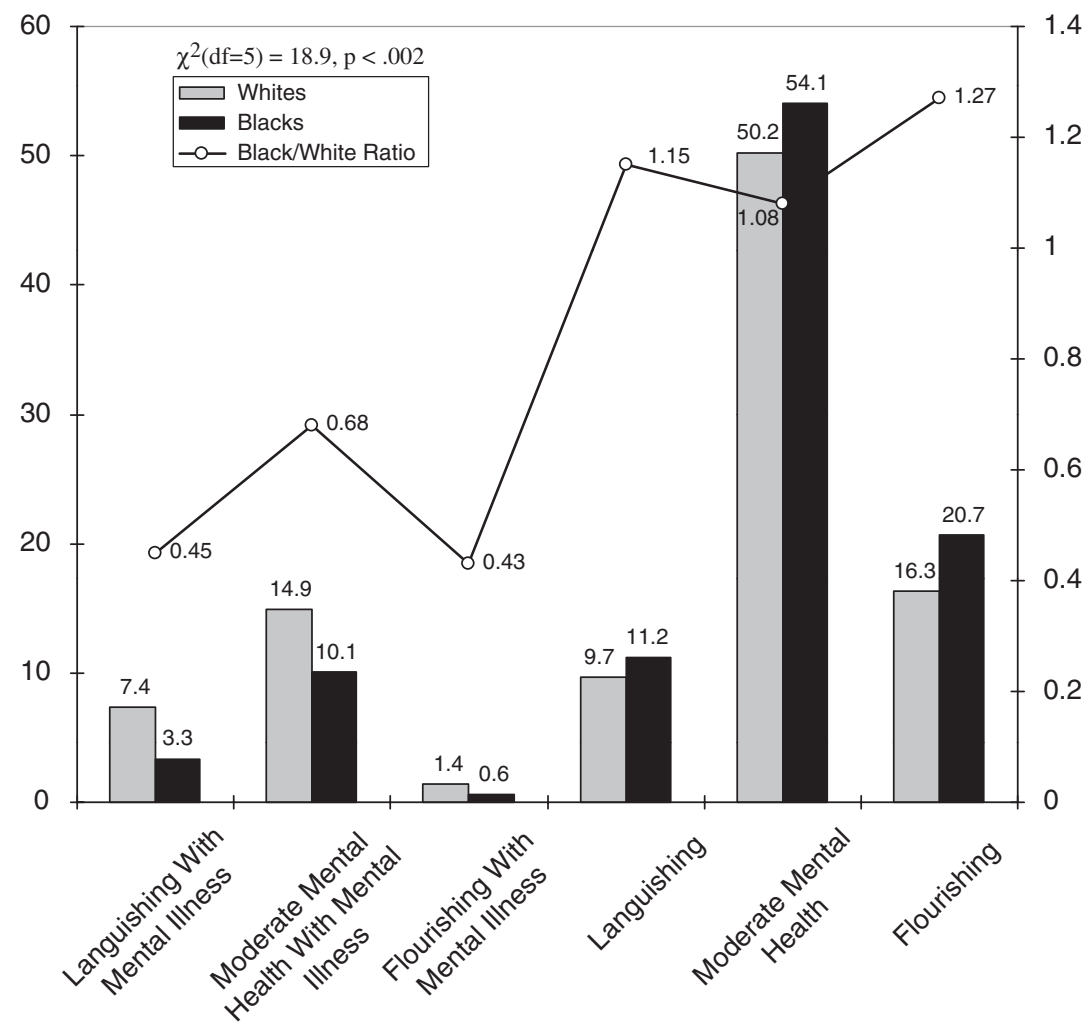

Figure 1

Unadjusted prevalence of complete mental health status by race and Black-White ratios in the MIDUS national sample (sample weighted).

of mental health), moderate mental health, and flourishing (i.e., the presence of mental health; see the appendix for the categorical diagnostic criteria of the "mental health continuum"). This figure presents a reanalysis of data from the MIDUS presented in Keyes (2007), where I used the continuous assessment of mental health, which also showed that Blacks had a higher level of overall mental health than Whites at all levels of educational attainment and controlling for household income (see the appendix for a description of the MIDUS sample).

The ratios focusing on any mental disorder (i.e., mental illness and flourishing, mental illness and moderate mental health, and mental illness and languishing) are all substantially below 1.0, indicating that 
fewer Blacks than Whites had any mental illness. In addition, the Black-White ratio of flourishing and free of any mental illness clearly shows that more Blacks, before any adjustments for social inequality or discrimination, have better overall mental health than Whites. Thus, in the face of social inequality and discrimination, about $27 \%$ more Blacks than Whites are flourishing and free of any mental illness, indicating that Blacks exhibit resilience in terms of mental health. Although slightly more Blacks than Whites have moderate mental health, this ratio suggest that moderate mental health is about equally distributed by race. However, about $15 \%$ more Blacks than Whites are languishing and yet free of mental illness, suggesting that, for a small portion of the Black population, the racial inequalities result in the negative outcome of the absence of mental health.

Although the Black advantage in mental health presents something of a paradox, this form of resilience - that is, mental health in the face of adversities that result in physical disease - is not unprecedented. In the context of aging, especially late life, resilience is instantiated by the maintenance of mental health despite the onset and increase in chronic physical conditions. This is seen as resilience because the onset of physical disease and conditions (e.g., heart disease) pose adaptive challenges. Thus, a large volume of research reveals strong associations - or comorbidity-between a host of physical diseases and conditions with caseness for, and number of symptoms of, mental illness (Keyes, 2004, 2005a). At all ages, but increasingly with age, research shows rates of mental disorders are higher among individuals with increased physical disease and physical limitation. With age, physical and mental illness tend to be comorbid because mental illness can be a prospective cause of physical conditions (e.g., heart disease) and, conversely, the onset of physical illness can be a cause of mental illness. In the latter example, physical disease is viewed as an adversity; the ability to maintain mental health in the face of such adversity is, by definition, resilience. The Black-White paradox represents the same form of resilience-the ability to maintain good mental health in the face of physical disease.

\section{Discrimination and Mental Health}

The focus on this special issue of resilience is on the topic of common sources of adversity or risk. Social hierarchies and therefore social inequalities are commonplace throughout human history, precisely 
because they solve, according to sociologists (e.g., Wrong, 1994), the problem of social disorder. That is, the placement of individuals into a social hierarchy means that they have been ascribed (e.g., due to fixed status characteristics like sex and race) and have achieved (e.g., educational attainment, occupation and its associated prestige, and thereby income) a social rank in the social system. As Sapolsky's (1990) studies of olive baboons have made so poignant, social rank in the dominance hierarchy creates social order by determining a priori access to desired resources whose allocation would otherwise require aggressive contests each time that resource is desired. Higher ranking individuals get the better of everything - more choices, better access to food, sex, and sleeping, and more grooming - than lower ranking members. This way of creating social order comes at the cost of displacing disadvantage and thereby stress onto a subpopulation rather than onto the entire population. In his way, social hierarchy is the lesser of two evils: Without it, the entire population suffers equally, and, with it, only a relative few suffer and thereby more of the population can live longer and healthier lives. Sociologically, then, social inequality is a common adversity that is the byproduct of the functional placement of social hierarchy to create social order.

Ideally, the sorting of individuals into the lower social rank is based on a mechanism that is random or developmentally temporary. The problem, of course, with the creation of social rank is that it is not random, and many individuals experience disadvantage all of their lives. This nonrandom mechanism in human beings is called discrimination. Racial minorities in the United States have historically faced stark social inequalities that result in large part from discrimination and continue to this day. Compared with Whites, Blacks are more likely to experience worse outcomes on literally all measures of inequality: lower educational outcomes, lower household incomes, higher rates of unemployment or unstable employment, jobs with lower occupational prestige, higher residential segregation, lower rates of home ownership, higher rates of incarceration, and, particularly among males, greater exposure to violence (Massey \& Denton, 1998; Williams, 1999; Wilson, 1987).

Using the MIDUS study - which is the data source for this paper and the Black-White differential in mental health-Kessler, Mickelson, and Williams (1999) reported the prevalence and distribution of perceived discrimination. Using a multi-item instrument that assessed both major and daily discriminatory experiences, they 
found that perceived discrimination is common in the total population, with $33.5 \%$ of respondents reporting exposure to major lifetime discrimination and $60.9 \%$ reporting exposure to day-to-day discrimination. Data from the Kessler et al. (1999) paper are presented in Figure 2. Figure 2a shows the 11 instances of perceived major discrimination as measured in the MIDUS study and the proportion of Blacks versus Whites who reported experiencing a specific form of discrimination. Other than being forced to leave a neighborhood, where Whites and Blacks have low and about equal experiences of discrimination, Blacks report higher levels on the other 10 instances of lifetime discrimination. Figure $2 \mathrm{~b}$ shows the nine possible forms of daily discrimination as measured in the MIDUS. As with major discrimination, more Blacks than Whites report experiencing daily discrimination. Indeed, at least one third to $46 \%$ of Blacks report experiencing seven of the nine forms of discrimination on a daily basis.

Moreover, Figure 3 shows that the Blacks in the MIDUS national study attribute their experiences of discrimination to their race (and ethnicity), followed by "other reasons" that had not been queried. It is possible that the cause of Blacks' discrimination being attributed to "other reasons" may include such things as their neighborhood (i.e., where they live), what they live in (e.g., mobile home or trailer park), if they have White friends or date Whites, and so forth. In sum, more Blacks experience more forms of discrimination than Whites, and about 9 of every 10 Blacks attribute the discrimination to their race.

Two studies using nationally representative probability samples have found that self-reports of discrimination are linked with physical and psychological distress (Clark, Anderson, Clark, \& Williams, 1999). Increased discrimination is associated with increased physical disease and higher distress. Moreover, the Ryff et al. (2003) study revealed a strong and negative association with the MIDUS measure of perceived discrimination with reduced levels on all six measures of psychological well-being. In the Kessler et al. (1999) paper, perceived lifetime discrimination in the MIDUS was associated with increased risk and levels of mental illness (e.g., major depressive episode). The strength of the adjusted associations of perceived discrimination with level of mental illness symptoms was comparable, according to Kessler et al. (1999), to the strength of the associations customarily found between major life events (e.g., death of a spouse) with mental 


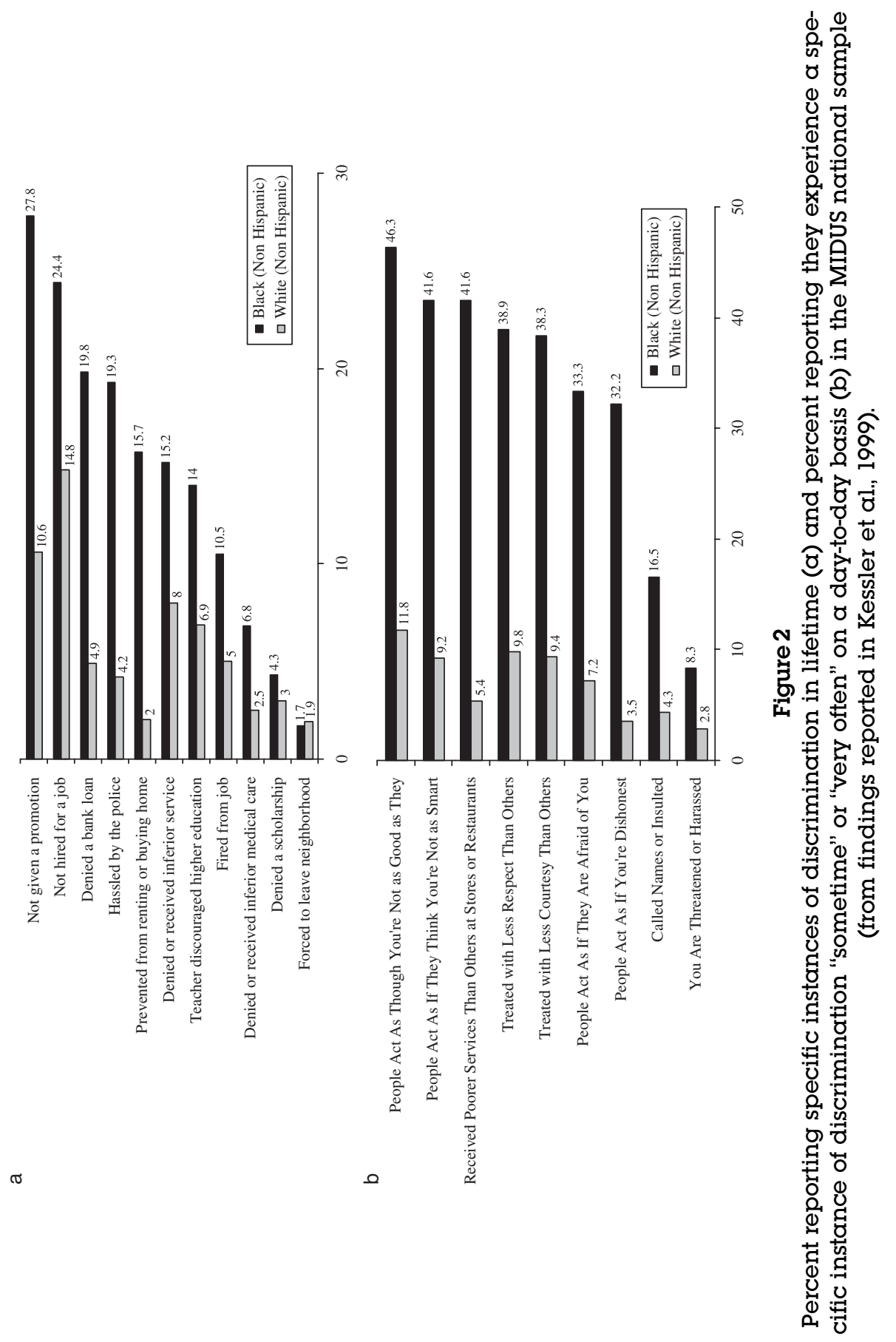




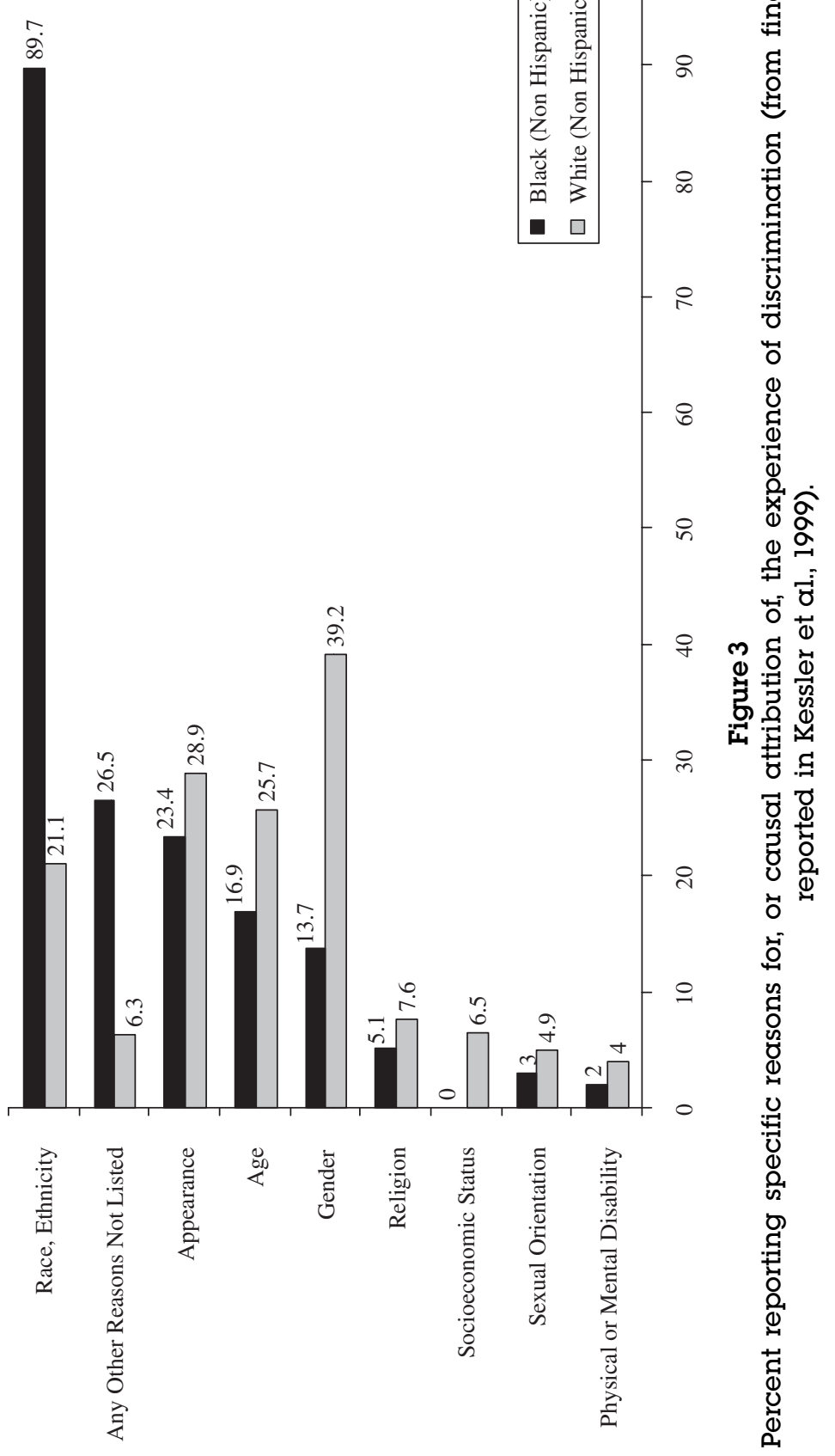


illness. Paradies's (2006) review of 138 quantitative studies measuring discrimination in nationally representative population studies revealed, in $72 \%$ of the studies, a positive association between selfreported discrimination and negative mental health outcomes and, in $62 \%$ of the studies reviewed, a positive association between increased discrimination and negative health behaviors such as alcohol and substance use and abuse.

In sum, perceived discrimination is a potent stressor (i.e., risk factor). Blacks report greater exposure to discrimination than Whites, and most Blacks attributed the discrimination to their race. Yet most studies that seek to explain racial disparities in mental health do not find that it explains the disparities, because there are either no race disparities in mental illness or Blacks report lower levels of mental disorders than Whites (Kessler et al., 1994; Williams \& Harris-Reid, 1999).

On the other hand, perceived discrimination plays an important part in explaining differences in levels of the various signs, or symptoms, used to diagnose positive mental health (Williams, Yu, Jackson, \& Anderson, 1997). The Ryff et al. (2003) paper focused on the six dimensions of psychological well-being, which form part of the Keyes (2002) diagnosis of the mental health continuum. In the Ryff et al. (2003) paper, we showed that, after controlling for educational differences, levels of all six dimension of psychological well-being were higher in the MIDUS Blacks than the MIDUS Whites. However, the Black advantage over Whites in levels of psychological well-being increased after adding the scale of overall perceived discrimination to each regression equation. This does not mean that discrimination is good for psychological well-being. On the contrary, it means the following: Were it not for discrimination, levels of psychological well-being would be even higher for Blacks than Whites. By statistically controlling discrimination, we are in effect looking at what levels of well-being might be in a world where there was both equal education and equal (or no) discrimination between Blacks and Whites - that is, a world where there were no race disparities in educational attainment and no race disparities in exposure to discrimination. This ideal world does not yet exist except in the statistical modeling sense; in this world, Blacks would have even better psychological well-being than Whites.

The dimensions of psychological well-being reflect only 6 of the 13 dimensions of subjective well-being that constitute the list of signs of the presence or absence of mental health. My assessment of the 
mental health continuum includes five dimensions of social well-being and two facets of emotional well-being (i.e., positive affect and satisfaction with life). I therefore ran the same regression models (including the same controls) we used in the Ryff et al. (2003) paper using the MIDUS sample and using the social well-being and emotional well-being outcomes. The point of this exercise was to estimate whether and to what degree perceived discrimination suppressed these dimensions of positive mental health besides the six dimensions reported in Ryff et al. (2003).

The results displayed in Figure 4 indicate that Blacks have lower levels on 1 - that is, social acceptance - of the 13 facets of positive mental health. Fifty-five percent of the gap between Blacks and Whites in social acceptance is explained by Blacks' higher exposure to discrimination. In this case, were it not for discrimination, Blacks would be almost as accepting of other people as Whites. (Note: Blacks remain less socially accepting than Whites even after controlling for level of perceived discrimination.)

Figure 4 also reveals that the other 12 dimensions of positive mental health are suppressed by discrimination, but some more than others. Six dimensions of mental health - social coherence, social growth, social integration, self acceptance, autonomy, and environmental mastery - are highly suppressed by discrimination. When discrimination is added to the regressions, the gap between Blacks and Whites (i.e., the Black advantage) increased by $65 \%$ in the case of environmental mastery up to $89 \%$ in the case of social coherence. In turn, three dimensions-positive affect, positive relations with others, and personal growth - are suppressed moderately by discrimination. When discrimination is added to these regressions, the gap between Blacks and Whites (i.e., the Black advantage) increased by $39 \%$ for personal growth and up to $47 \%$ in the case of positive affect. The final three dimensions - social contribution, life satisfaction, and purpose in life - are suppressed mildly by discrimination. Here, the gap between Blacks and Whites increased by only $20 \%$ for purpose in life and up to $30 \%$ in the case of social contribution.

In 12 of the 13 signs of mental health, Blacks would have even higher levels than Whites were it not for the fact that Blacks experience much more discrimination than Whites, and perceived discrimination is negatively associated with all facets of positive mental health. Although it suppresses all 12 of these dimensions of mental 


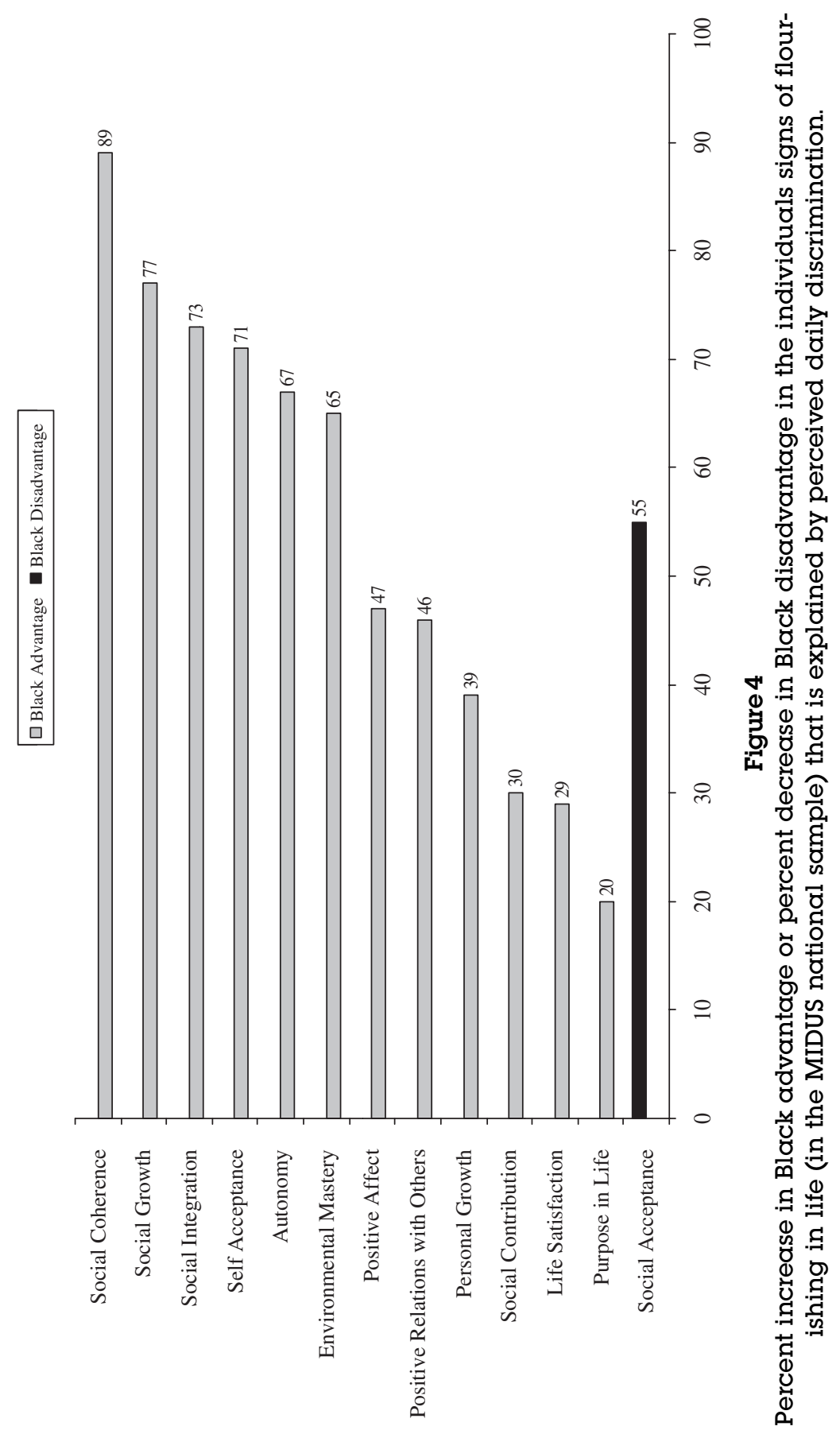


health, discrimination in particular most strongly inhibits Blacks from realizing environmental mastery, autonomy, self-acceptance, social integration, social growth, and social coherence. These six dimensions are facets of positive (eudaimonic) functioning, three of which reflect psychological well-being (i.e., mastery, autonomy, and acceptance of self) and three that reflect social well-being (i.e., coherence, integration, and contribution to society).

\section{What Might Explain the Resilience in the Black Community?}

First, is it resilience, or are the findings of the Black advantage in overall mental health a sampling artifact or a reflection of narcissism? The higher rate of premature mortality in the Black population means that the unhealthiest Blacks are selected out of the population, leaving behind healthier individuals for selection into national probability samples. This is particularly likely among Black males, who have the lowest life expectancy at birth, estimated to be about 69 years at birth as of the year 2005 (Harper, Lynch, Burris, \& Smith, 2007). However, Black females continue to have a higher life expectancy at birth than White males (Harper et al., 2007), which means that the selection effect should not be as pronounced in Black females as in Black males. If Black females also show the advantage in overall mental health, compared with Whites (males or females), this should provide evidence that the selection effect does not provide a satisfactory explanation for the findings reported here. Indeed, as reported in Keyes (2007), there was a main effect of race and an interaction of race and gender when using the continuous measure of overall mental health as the dependent variable. White females reported lower mental health than White males, whereas there was no difference in mental health between Black males and females. Thus, Black females as well as males report better overall mental health than Whites.

Similarly, and in presenting these findings in several talks, an audience member invariably raises the question of the validity of Blacks' responses to the items on the positive mental health questionnaire. This response mirrors the debate that has surrounded the findings of the Black advantage in self-esteem (Crocker \& Major, 1989; Gray-Little \& Hafdahl, 2000), because self-esteem has been positively correlated with narcissism (Watson, Hickman, \& Morris, 
1996), and Blacks report slightly higher levels of narcissism than Whites (Twenge \& Crocker, 2002). Does flourishing in Blacks really mean better mental health or is it a reflection of defensiveness, denial, distortion, or inflated views of themselves? This, of course, remains an empirical question for future research. Assuming for the moment that flourishing, whether in Blacks or Whites, is associated with some narcissism, the question is whether this is adaptive and functional or maladaptive and dysfunctional to other forms of health and functioning in life. After all, theorists since Freud have speculated that some degree of narcissism is either necessary for functioning or it contributes to adaptation.

In prior papers employing the MIDUS data set, I have found that the mental health diagnosis is strongly associated with risk of major depressive episode in the past year, health limitations of instrumental activities of daily living (IADLs, which indicate disability), and work impairments in the past month (missing a half day or a whole day of work; see Keyes, 2002, 2005b). Individuals who are flourishing report the lowest prevalence of major depressive episodes, the lowest prevalence of IADLs (i.e., whether a respondent says his or her health limits any of nine activities "a lot") ${ }^{3}$ and with the lowest prevalence of any work impairment (i.e., whether a respondent missed a whole day or cut back work by a half day at least one time in the past 30 days). For each of these outcomes, there was a relatively strong and graded relationship with mental health such that adults with moderate mental health functioned worse than adults who were flourishing, and adults who were languishing functioned worse than adults who were moderately mentally healthy. The question is whether flourishing in Blacks is associated with the same beneficial outcomes as in Whites.

Findings reported in Figure 5a-c suggest that the mental health continuum is associated with depression, IADLs, and work impairment in the same fashion for Blacks as for Whites. The chi-squared statistics testing the association of all three outcomes with the mental health continuum were statistically significant at $p<.05$ for Blacks

\footnotetext{
${ }^{3}$ The activities of daily living include lifting and carrying groceries, bathing or dressing oneself, climbing several flights of stairs, bending (kneeling or stooping), walking more than a mile, walking several blocks, walking one block, vigorous activity (running, lifting heavy objects), and moderate activity (bowling or vacuuming).
} 

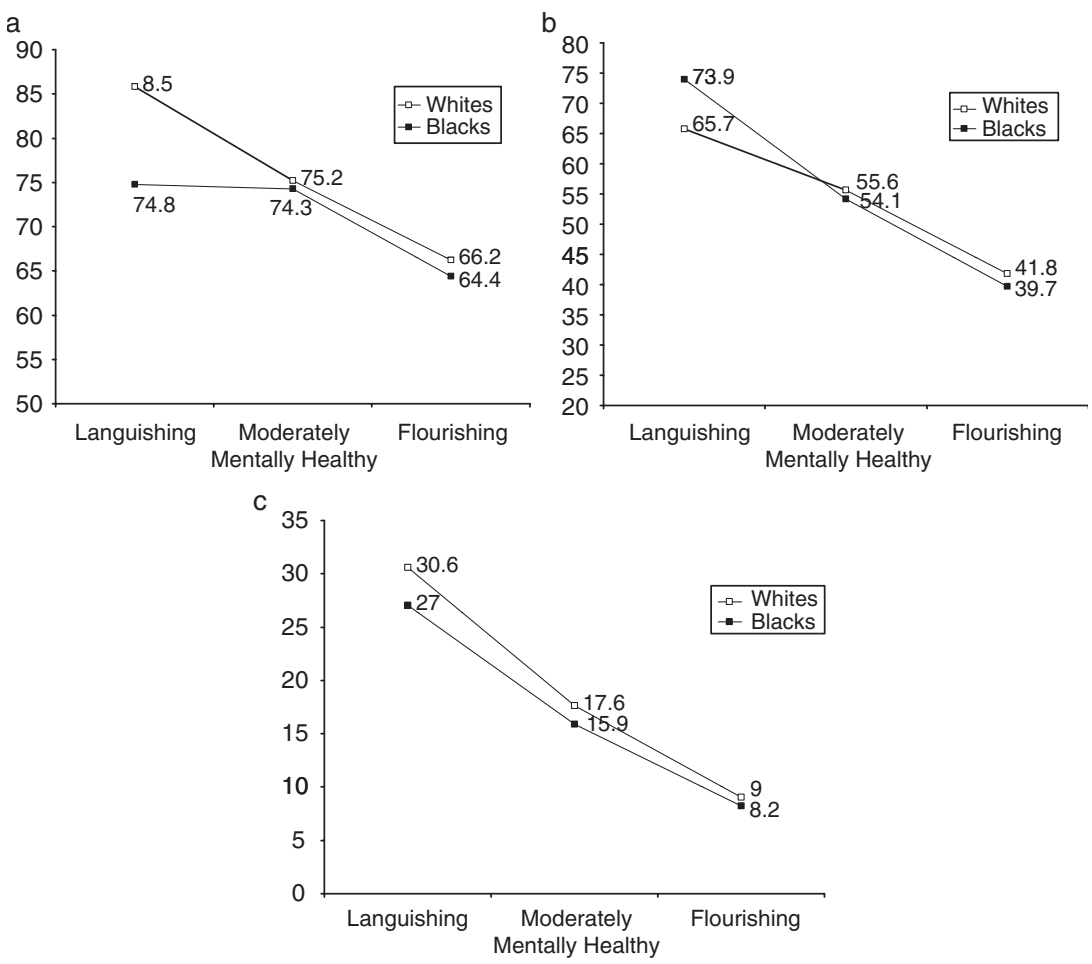

Figure 5

Percent with any chronic physical condition (a), any high limitation of instrumental activities of daily life (b), and any work days lost or cutback (c) by level of mental health and by race (sampled weighted).

and for Whites. Thus, and compared with adults with moderate mental health or languishing, flourishing Blacks and Whites report the lowest prevalence of major depressive episodes, the fewest IADLs, and the least amount of work impairment. Although this does not rule out the possibility that flourishing is associated with narcissism or whether narcissism is in part the basis for flourishing in Blacks or Whites, these findings suggest that flourishing is adaptive for Blacks as for Whites in terms of three important indicators of burden to society: depression, disability, and work loss.

Assuming, then, that flourishing in Blacks is a form of resilience, what adaptive mechanisms might explain this source of strength? Perhaps the most obvious source is religion. The institution of re- 
ligion and religious practices such as worship has played a significant role in the Black community (Taylor, Chatters, \& Levin, 2003). Religious attendance is consistently higher among Blacks than Whites (Taylor, Chatters, Jayakody, \& Levin, 1996). In turn, numerous studies have shown that religious attendance is associated with increased levels of subjective well-being and lower psychological distress and mental illness in general (Ellison, Boardman, Williams, \& Jackson, 2001) and in the Black community (Ellison, 1995). Future research is likely to show that religion is a protective factor for Blacks in the face of inequality and discrimination.

Other avenues for understanding the mental health resilience in the Black population are racial socialization (Fischer \& Shaw, 1999) and group identification (Branscombe, Schmitt, \& Harvey, 1999), because they are both important for dealing with discriminatory experience (e.g., explaining the discrimination or refuting the stereotypes). In addition, racial socialization and identification with one's race help to instill meaning, purpose, pride, and commitment to the goal of selfdevelopment. Applied to family life, the cultural identity of parents and what it implies for cultural socialization of children (Spencer, Swanson, \& Glymph, 1996) may be relevant for promoting aspects of eudaimonic well-being such as self-acceptance and social integration.

How identification and socialization instill meaning remains a topic of future research. Here, two possible areas for inquiry among personality psychologists are generativity and personal narratives. McAdams and colleagues have done exceptional research that may be relevant to understanding the Black-White paradox in health in at least two ways. First, compared with White parents, Black parents report higher levels of generative concern (e.g., helping the next generation), engage in more generative behaviors, and are more likely to view themselves as role models in their roles as parents (Hart, McAdams, Hirsch, \& Bauer, 2001). In the MIDUS study, generativity was measured in terms of social responsibility, generative concern, generative behaviors, and personality (i.e., using the Loyola Generativity Scale). As predicted, we found that higher levels on all four forms of generativity additively (i.e., in multiple regressions) contributed to higher levels of overall social well-being and overall psychological well-being, which are two key domains of flourishing in life (i.e., positive mental health). The higher levels of generativity found by McAdams, Reynolds, Lewis, Patten, and Bowman (2001) in Blacks may help to explain some of their mental health resilience. 
Second, narrative life stories that include sequences of redemption and contamination, and these life narratives are associated with wellbeing and mental health outcomes (McAdams et al., 2001). A narrative of redemption involves a sequence of life stories in which the individuals' reaction to adversity involves, first, a negative emotion that, through struggle and learning, leads to a positive emotion and outcome. Conversely, a narrative of contamination involves a sequence of events and experiences of a life story in which an individual's reaction to positive emotion, which usually follows accomplishment of a goal or an unintended success, is followed by a negative emotion that reflects learning something unpleasant about life or oneself. As reported by McAdams et al. (2001), midlife adults whose life stories include more redemption than contamination sequences tended to report higher levels self-esteem, satisfaction with life, and lower levels of depressive symptoms. In turn, college students whose life stories include more redemption sequences also tended to report higher levels on five of the six scales of psychological well-being (not on the scale of autonomy) as well as higher satisfaction with life (McAdams et al., 2001), and these outcomes are part of the hedonic (i.e., satisfaction) and eudaimonic (i.e., psychological well-being) cluster of signs of flourishing mental health.

Frankl (1959) argued that it is not suffering per se but suffering without meaning that is pathogenic and undermines one's will for living. From his experiences in a concentration camp during World War II, Frankl (1959) observed in himself and others that meaning in life is important under all conditions and that individuals suffer more when their search for meaning is lost, blocked, or destroyed. Frankl's point is that the ability to create or find meaning to one's life, when lived under adversity, provides an important source of resilience. Studies show that a lack of meaning and purpose in life is associated with increased psychopathology, suicidal ideation, and problems of adjustment to trauma (Heisel \& Flett, 2004; Thompson, Coker, Krause, \& Henry, 2003), whereas higher levels of purpose and meaning in life are associated with more religious beliefs, more civic engagement, more dedication to social causes, and greater investment in life-affirming values and goals (Zika \& Chamberlain, 1992). Purpose in life and dedication to others can be forged by challenges of living in a society of inequality and discrimination such that one's life becomes a vocation for social change and justice. 
Edelman (1999) epitomizes this view of the origin of meaning in one's life: "As a black girl growing up in a small segregated southern town, I could never take anything for granted and never for a moment lacked a purpose worth fighting, living, and dying for, or an opportunity to make a difference" (p. xiii).

Coping is a critical reaction to adversities that can determine whether individuals are resilient, but not all forms of coping may confer resilience. Although tactics that are focused on controlling or mitigating one's emotional sequelae can be helpful in some circumstances, the bulk of empirical studies suggests that it is problem-focused coping that is more likely to be protective (Monat \& Lazarus, 1991). According Monat and Lazarus (1991), "Problem-focused coping refers to efforts to improve the troubled person-environment relationship by changing things, for example, by seeking information about what to do, by holding back from impulsive and premature actions, and by confronting the person or persons responsible for one's difficulty" (p. 6). Krieger (1990) found that Black women who coped more actively with discrimination (e.g., talking about it to others, dealing with it directly) were less likely to have high blood pressure and hypertension than women who passively accepted discrimination as a fact of life.

During the same period that Lazarus was pioneering his work on stress and coping, James (James, Hartnett, \& Kalsbeek, 1983) was doing pioneering work on a form of active (problem-focused) coping among Black Americans. Named after the legend of John Henry-a story of accomplishments by hard work, strength, perseverance, and endurance - this form of active coping is known as John Henryism ( JH). For James (1994), JH coping is a form of persistent and high effort coping that is required of racial minorities who wish to succeed in a world where they experience significant discrimination (i.e., obstacles to succeeding). James' (1996) scale to measure JH coping consists of 12 items to which respondents indicate the degree to which each item is true or false. Examples of $\mathrm{JH}$ coping items include, "I've always felt that I could make of my life pretty much what I wanted to make of it," "Once I make up my mind to do something, I stay with it until the job is completely done," "I like doing things that other people thought could not be done," "When things don't go the way I want them to, that makes me work even harder," and "It's not always easy, but I manage to find a way to do the things I really need to get done." 
James hypothesized that $\mathrm{JH}$ coping among Blacks could explain the high rates of hypertension among Blacks, because $\mathrm{JH}$ coping could create risk factors for cardiovascular disease among individuals with low resources, particularly lower socioeconomic standing in education as well as employment and income. Several studies have confirmed this hypothesis, showing that Blacks with higher scores on the John Henryism Scale among those with low levels of education or low socioeconomic status are more likely to have hypertension and higher blood pressure (James et al., 1983; James, Keenan, Strogatz, Browning, \& Garrett, 1992; James, Strogatz, Wing, \& Ramsey, 1987).

There has been very little research into the relationship of $\mathrm{JH}$ coping with subjective well-being measures. In a sample of Black males with high socioeconomic status, Bonham, Sellers, and Neighbors (2004) found a positive association between increased levels of John Henryism and better self-rated overall health. There have been no studies I could locate that linked John Henryism to the subjective well-being measures that are similar to my assessment of positive mental health. Moreover, I could find only one study that tested the association of John Henryism with depressive symptoms (Neighbors, Njai, \& Jackson, 2007). Neighbors et al. did not find a main effect of John Henryism on depressive symptoms in African Americans or in the sample of Caribbean Blacks. In both Black subsamples, those with higher endorsement of social dominance beliefs (i.e., winning at all costs is important; one should try to get ahead by any means) had higher levels of depression. Only in the Caribbean Blacks, however, did the relationship of social dominance with depression depend on John Henryism; here, the interaction term was negative, indicating that, with higher levels of John Henryism, the positive relationship of social dominance with depression was mitigated.

Neighbors et al.'s (2007) findings suggest that John Henryism plays something of a protective role among Caribbean Blacks with high social dominance beliefs, whereas it is unrelated with depressive symptoms among Blacks of African descent. Because John Henryism shows a strong association with risk factors for physical disease, this construct is one candidate for explaining the Black-White paradox in health. Future research should investigate whether increased John Henryism results in increased levels of flourishing at the same time it increases physical illness risk factors. That is, high JH coping among Blacks may compromise physical health among those with low so- 
cioeconomic standing, whereas high $\mathrm{JH}$ coping among those same individuals could maintain a sense of dignity and meaning to one's life. This situation is reflected in one of the $\mathrm{JH}$ coping items where individuals say they manage to find a way to do the things that really need to get done, even though doing so may not always be easy.

\section{Conclusion}

Mental health is a positive state of well-being, as conceptualized by the World Health Organization (2004), which builds on the work on the mental health continuum and the concept of flourishing mental health (Keyes, 2002). Mental illness, on the other hand, is a persistent deviation of normal functioning that results in emotional suffering and significant impairment of functioning at a high cost to society. The absence of mental illness does not mean the presence of flourishing mental health. In both the MIDUS sample of adults (Keyes, 2005b) and in the nationally representative sample of adolescents (ages 12-18) in the Child Development Supplement Study (Keyes, 2009), confirmatory factor analyses supported the hypothesized "two-continua" model of mental health and illness. In both adults and adolescents, flourishing individuals function markedly better than individuals who are otherwise free of a mental illness but have moderate or low levels of well-being. This has been shown in terms of mental illness (major depressive episode, panic disorder, generalized anxiety, alcohol dependence in adults and depressive symptoms in adolescents), work impairments in adults, conduct problems in youth, chronic physical conditions and cardiovascular disease in adults, health care utilization in adults, and psychosocial assets (intimacy, perceived control, clear life goals, self-reported resilience in adults and positive self-concept, self-efficacy, closeness to significant others, and perceived integration into school in adolescents; see Keyes, 2009). Although the distinctions along the mental health continuum clearly matter for individuals who are free of a mental illness, those same distinctions differentiate levels of functioning among adults and youth with a mental illness - with flourishing individuals who have a mental illness functioning better than those with moderate mental health, who in turn function better than individuals who are languishing and have a mental illness.

Although they have clear implications for health policy and programs (see, e.g., Keyes, 2007), the findings of the distinction and 
function of the mental health continuum from the mental illness continuum have implications for the conception and study of resilience. Most studies of resilience in mental health have conceptualized the outcome of resilience in terms of the absence of the diagnosis of (or screening for) a mental disorder. That is, youth and adults who are at risk but do not have a mental illness are considered resilient. The two-continua model reveals that individuals otherwise free of mental illness may be languishing rather than flourishing, because individuals free of mental illness but languishing often function as poorly, and sometimes worse, than individuals with a mental illness but with moderate mental health or flourishing (see Keyes, 2007). As such, freedom from mental illness should not be considered a de facto sign of resilience without distinguishing youth and adults who are languishing (i.e., not resilient) from those who are flourishing (i.e., are resilient).

On the other hand, resilience may also be observable among individuals with a current mental disorder. It may also be a useful strategy to study resilience among those with a current mental disorder by conceptualizing it in terms of the ability to maintain or attain some level of positive mental health (e.g., moderate mental health or even flourishing) from individuals who are currently mentally ill and languishing. When studied over time, mentally ill patients receiving treatment can be studied so as to discover the predictors of positive recovery - which I would conceptualize as movement from languishing toward moderate mental health and ultimately toward flourishing - from negative recovery, which would be the mitigation of mental illness symptoms.

Until now, evidence for the Black-White paradox was indirect, because studies showed equal or lower rates of mental disorders among Blacks compared with Whites. However, the research on the mental health continuum and flourishing indicates that the absence of mental illness does not mean mental health. The evidence reviewed and presented in this paper therefore is direct evidence for the Black-White paradox in health. Blacks have higher rates of complete mental health - flourishing and free of mental illness - than Whites. This finding is paradoxical insofar as Blacks, compared with Whites, face greater levels of social inequality and discrimination that explain much, and sometimes all, of the Black disadvantage in terms of premature mortality and physical disease. Although inequality and discrimination increase the risk of physical morbidity among Blacks, 
they do not entirely suppress the chances of positive mental health in Blacks. In fact, before making any statistical adjustments in sociodemographic variables, about $27 \%$ more Blacks than Whites are flourishing and free of mental disorder. When perceived discrimination is entered into regression models with relevant covariates (e.g., educational attainment), the gap increases between Blacks and Whites on 12 of the 13 signs of flourishing. Thus, were it not for social inequalities in general and discrimination in particular, Blacks would have even better mental health than Whites. Discrimination, in short, suppresses Blacks' potential to fully flourish in life.

Notwithstanding exposure to discrimination and dramatic social inequalities, Blacks exhibit resilience in mental health. Several alternative explanations for this resilience were reviewed in this paper. Selection bias that removes the unhealthiest individuals out of the population remains an important issue in this line of research. However, in the MIDUS data, the finding that Black women also exhibited better overall mental health than White males or females diminishes the selection bias explanation, because Black women have slightly higher life expectancy at birth than White males. Whether flourishing among Blacks reflects narcissism is, in my opinion, an important issue only if it is sufficiently high to undermine the benefits associated with this desirable state. Indeed, new analyses presented in this paper indicate that the mental health continuum was associated with major depressive episodes, limitations of instrumental activities of daily living (a measure of disability), and work impairments to the same extent among Blacks as Whites. Blacks who are flourishing do as well as, if not slightly better than, flourishing Whites in terms of low rates of depression, low disability, and low work impairment. Notwithstanding any narcissism, flourishing is as adaptive for Blacks as for Whites.

The eminent sociologist and civil rights activist W.E.B. Du Bois penned the following quote in 1957, which was read 6 years later at his funeral (Buckley, 2008): "As you live, believe in life! Always human beings will progress to a greater, broader, and fuller life." Having lived a long and productive life as a Black man and scholar in a racist society, Du Bois ended his life with hope and optimism, sounding more like Abraham Maslow and the concept of self-actualization before there was the humanistic movement and long before the rise of positive psychology. How was Du Bois able to maintain 
his belief in life and the potential for personal growth, to implore, through this final act of generativity, future generations to also believe in life? How, for that matter, are the Blacks, as featured in the nationally representative MIDUS study, able to flourish in the face of inequality and discrimination?

My review of potential mechanisms of resilience in the Black community is not meant to be exhaustive; it is a selective look at what I thought might be some of the more obvious and interesting directions for future inquiry. Religion and spirituality are important sources of health and well-being for all, but it may play a particularly important role in maintaining positive mental health in the face of significant obstacles to success. Racial socialization and ethnic identification may also infer resilience by providing individuals with an explanatory style for discrimination (cf. Crocker \& Major, 1989) that also instills pride and commitment to the goal of personal growth. The ability to construct meaning in life through the construction of life stories with more sequences of redemption remains a possible source of resilience among Blacks. To my knowledge, there have been no studies of whether Blacks create more life narratives with redemption sequences than Whites and whether the amount of redemptive sequences in life stories is as, or even more, important for the well-being of Blacks than Whites.

Generativity, whether it is reflected in motivation or behavior, is related to higher levels of eudaimonic well-being, and, separately, studies have shown that these forms of generativity are prominent among Blacks. The notion that "we shall overcome" is perhaps as important a legacy to leave behind to future generations as particular skills and knowledge, and in doing so, perhaps this protects Black adults' mental health from the pathogenesis of discrimination. Last, direct as opposed to passive forms of coping among Blacks are a likely candidate for helping to understand their mental health resilience. From the perspective of the Black-White paradox, James's (1994) construct of John Henryism coping is very relevant, because studies show that high levels of it are associated with increased risk factors for physical disease (e.g., hypertension). It is plausible that the active coping embodied in high levels of John Henryism might be conducive to maintaining mental health in the face of discrimination, because it resembles Du Bois' faith in the potential for personal growth if individuals will continue to believe in life. 


\section{REFERENCES}

Bonham, V. L., Sellers, S. L., \& Neighbors, H. W. (2004). John Henryism and selfreported physical health among high-socioeconomic status African American men. American Journal of Public Health, 94, 737-738.

Branscombe, N. R., Schmitt, M. T., \& Harvey, R. D. (1999). Perceiving pervasive discrimination among African Americans: Implications for group identification and well-being. Journal of Personality and Social Psychology, 77, 135-149.

Breslau, J., Su, M., Kendler, K., Aguilar-Gaxiola, S., \& Kessler, R. C. (2005). Lifetime risk and persistence of psychiatric disorders across ethnic groups in the United States. Psychological Medicine, 35, 317-327.

Buckley, K. W. (2008). W.E.B. Du Bois: A concise biography. Retrieved March 30, 2008, from: http://www.library.umass.edu/spcoll/collections/dubois/biography.htm

Clark, R., Anderson, N. B., Clark, V. R., \& Williams, D. R. (1999). Racism as a stressor for African Americans. American Psychologist, 54, 805-816.

Crocker, J., \& Major, B. (1989). Social stigma and self-esteem: The self-protective properties of stigma. Psychological Review, 96, 608-630.

Dunlop, D. D., Song, J., Lyons, J. S., Manheim, L. M., \& Chang, R. W. (2003). Racial/ethnic differences in rates of depression among preretirement adults. American Journal of Public Health, 93, 1945-1952.

Edelman, M. W. (1999). Lanterns: A memoir of mentors. New York: HarperCollins.

Ellison, C. G. (1995). Race, religious involvement and depressive symptomatology in a southeastern U. S. community. Social Science and Medicine, 40, 1561-1572.

Ellison, C. G., Boardman, J. D., Williams, D.R, \& Jackson, J. S. (2001). Religious involvement, stress, and mental health: Findings from the 1995 Detroit Area Study. Social Forces, 80, 215-249.

Fischer, A. R., \& Shaw, C. M. (1999). African Americans' mental health and perceptions of racist discrimination: The moderating effects of racial socialization experiences and self-esteem. Journal of Counseling Psychology, 46, 395-407.

Frank1, V. E. (1959). Man's search for meaning. Boston: Beacon Press.

Gray-Little, B., \& Hafdahl, A. R. (2000). Factors influencing racial comparisons of self-esteem: A quantitative review. Psychological Bulletin, 126, 26-54.

Harper, S., Lynch, J., Burris, S., \& Smith, G. D. (2007). Trends in the BlackWhite life expectancy gap in the United States, 1983-2003. Journal of the American Medical Society, 297, 1224-1232.

Hart, H. M., McAdams, D. P., Hirsch, B. J., \& Bauer, J. J. (2001). Generativity and social involvement among African Americans and Whites adults. Journal of Research in Personality, 35, 208-230.

Heisel, M. J., \& Flett, G. L. (2004). Purpose in life, satisfaction with life, and suicide ideation in a clinical sample. Journal of Psychopathology and Behavioral Assessment, 26, 127-135.

House, J. S., Kessler, R. C., \& Herzog, A. R. (1990). Age, socioeconomic status, and health. Milbank Quarterly, 68, 383-411.

James, S. A. (1994). John Henryism and the health of African-Americans. Culture, Medicine, and Psychiatry, 18, 163-182. 
James, S. A. (1996). The John Henryism scale for active coping. In R. L. Jones (Ed.), Handbook of tests and measurements for Black populations (Vol. 2, pp. 415-425). Hampton, VA: Cobb \& Henry Publishers.

James, S. A., Hartnett, S. A., \& Kalsbeek, W. D. (1983). John Henryism and blood pressure differences among Black men. Journal of Behavioral Medicine, 6, 259-278.

James, S. A., Keenan, N. L., Strogatz, D. S., Browning, S. R., \& Garrett, J. M. (1992). Socioeconomic status, John Henryism, and blood pressure in Black adults: The Pitt County study. American Journal of Epidemiology, 135, 59-67.

James, S. A., Strogatz, D. S., Wing, S. B., \& Ramsey, D. (1987). Socioeconomic status, John Henryism and hypertension in Blacks and Whites. American Journal of Epidemiology, 126, 664-673.

Kessler, R. C., McGonagle, K. A., Zhao, S., Nelson, C. B., Hughes, M., Eshleman, S., et al. (1994). Lifetime and 12-month prevalence of DSM-III-R psychiatric disorders in the United States. Archives of General Psychiatry, 51, 8-19.

Kessler, R. C., Mickelson, K. D., \& Williams, D. R. (1999). The prevalence, distribution, and mental health correlates of perceived discrimination in the United States. Journal of Health and Social Behavior, 40, 208-230.

Keyes, C. L. M. (2002). The mental health continuum: From languishing to flourishing in life. Journal of Health and Social Behavior, 43, 207-222.

Keyes, C. L. M. (2004). The nexus of cardiovascular disease and depression revisited: The complete mental health perspective and the moderating role of age and gender. Aging and Mental Health, 8, 266-274.

Keyes, C. L. M. (2005a). Chronic physical disease and aging: Is mental health a potential protective factor? Ageing International, 30, 88-104.

Keyes, C. L. M. (2005b). Mental illness and/or mental health? Investigating axioms of the complete state model of health. Journal of Consulting and Clinical Psychology, 73, 539-548.

Keyes, C. L. M. (2007). Promoting and protecting mental health as flourishing: A complementary strategy for improving national mental health. American Psychologist, 62, 95-108.

Keyes, C. L. M. (2009). The nature and importance of positive mental health in America's adolescents. In R. Gilman, E. S. Huebner, \& M. Furlong (Eds.), The handbook of positive psychology in schools (pp. 9-24). New York: Routledge.

Krieger, N. (1990). Racial and gender discrimination: Risk factors for high blood pressure? Social Science and Medicine, 30, 1273-1281.

Levine, R. S., Foster, J. E., Fullilove, R. E., Fullilove, M. T., Briggs, N. C., Hull, P. C., et al. (2001). Black-White inequalities in mortality and life expectancy, 1933-1999: Implications for healthy people 2010. Public Health Reports, 116, 474-483.

Link, B. G., \& Phelan, J. C. (1995). Social conditions as fundamental causes of disease. Journal of Health and Social Behavior, Special No., 80-94.

Link, B. G., \& Phelan, J. C. (2002). McKeown and the idea that social conditions are fundamental causes of disease. American Journal of Public Health, 92, 730-732.

Massey, D., \& Denton, N. (1998). American apartheid: Segregation and the making of the underclass. Cambridge, MA: Harvard University Press. 
Masten, A. S., \& Coatsworth, J. D. (1998). The development of competence in favorable and unfavorable environments: Lessons from research on successful children. American Psychologist, 53, 205-220.

McAdams, D. P., Reynolds, J., Lewis, M., Patten, A. H., \& Bowman, P. J. (2001). When bad things turn good and good things turn bad: Sequences of redemption and contamination in life narrative and their relation to adaptation in midlife adults and in students. Personality and Social Psychological Bulletin, 27, 474-485.

Mirowsky, J., \& Ross, C. E. (2003). Social causes of psychological distress (2nd ed.). Hawthorne, NY: Aldine de Gruyter.

Monat, A., \& Lazarus, R. S. (1991). Stress and coping: An anthology. New York: Columbia University Press.

Mrazek, P. J., \& Haggerty, R. J. (Eds.). (1994). Reducing risks for mental disorders: Frontiers for prevention intervention research. Washington, DC: National Academy Press.

Neighbors, H. W., Njai, R., \& Jackson, J. S. (2007). Race, ethnicity, John Henryism, and depressive symptoms: The national study of American life adult reinterview. Research in Human Development, 4, 71-87.

Paradies, Y. (2006). A systematic review of empirical research on self-reported racism and health. International Journal of Epidemiology, 35, 888-901.

Riolo, S. A., Nguyen, T. A., Greden, J. F., \& King, C. A. (2005). Prevalence of depression by race/ethnicity: Findings from the National Health and Nutrition Examination Survey III. American Journal of Public Health, 95, 998-1000.

Ryff, C. D., Keyes, C. L. M., \& Hughes, D. (2003). Status inequalities, perceived discrimination, and eudaimonic well-being: Do the challenges of minority life hone purpose and growth? Journal of Health and Social Behavior, 44, 275-291.

Sapolsky, R. M. (1990). Stress in the wild. Science, 262, 116-123.

Spencer, M. B., Swanson, D. P., \& Glymph, A. (1996). The prediction of parental psychological functioning: Influences of African American adolescent perceptions and experiences of context. In C. D. Ryff \& M. M. Seltzer (Eds.), The parental experience in midlife (pp. 337-382). Chicago: University of Chicago Press.

Taylor, R. J., Chatters, L. M., Jayakody, R., \& Levin, J. (1996). Black and White differences in religious participation: A multisample comparison. Journal for the Scientific Study of Religion, 35, 403-410.

Taylor, R. J., Chatters, L. M., \& Levin, J. (2003). Religion in the lives of African Americans: Social, psychological, and health perspectives. Thousand Oaks, CA: Sage Publications.

Thompson, N. J., Coker, J., Krause, J. S., \& Henry, E. (2003). Purpose in life as a mediator of adjustment after spinal cord injury. Rehabilitation Psychology, 48, $100-108$.

Twenge, J. M., \& Crocker, J. (2002). Race and self-esteem: Meta-analyses comparing Whites, Blacks, Hispanics, Asians, and American Indians. Psychological Bulletin, 128, 371-408. 
Watson, P. J., Hickman, S. E., \& Morris, R. J. (1996). Self-reported narcissism and shame: Testing the defensive self-esteem and continuum hypotheses. Personality and Individual Differences, 21, 253-259.

Williams, D. R. (1999). Race, socioeconomic status, and health: The added effects of racism and discrimination. Annals of the New York Academy of Sciences, 896, 173-188.

Williams, D. R., \& Earl, T. R. (2007). Commentary: Race and mental healthMore questions than answers. International Journal of Epidemiology, 36, 758760.

Williams, D. R., Gonzalez, H. M., Neighbors, H., Nesse, R., Abelson, J. M., Sweetman, J., et al. (2007). Prevalence and distribution of major depressive disorder in African Americans, Caribbean Blacks, and non-Hispanic Whites. Archives of General Psychiatry, 64, 305-315.

Williams, D. R., \& Harris-Reid, M. (1999). Race and mental health: Emerging patterns and promising approaches. In A. V. Horwitz \& T. L. Scheid (Eds.), A Handbook for the study of mental health: Social contexts, theories, and systems (pp. 295-314). New York: Cambridge University Press.

Williams, D. R., Yu, Y., Jackson, J. S., \& Anderson, N. B. (1997). Racial differences in physical and mental health: Socio-economic status, stress and discrimination. Journal of Health Psychology, 2, 335-351.

Wilson, W. J. (1987). The declining significance of race: The truly disadvantagedThe inner city, the underclass, and public policy. Chicago: University of Chicago Press.

World Health Organization. (2004). Promoting mental health: Concepts, emerging evidence, practice (Summary report). Geneva: Author.

Wrong, D. H. (1994). The problem of social order: What unites and divides society. New York: Free Press.

Zika, S., \& Chamberlain, K. (1992). On the relation between meaning in life and psychological well-being. British Journal of Psychology, 83, 133145 . 


\section{APPENDIX}

Keyes's Categorical Diagnostic Criteria and Signs of Mental Health

\section{Hedonic (Emotional) Well-Being}

Criteria: Requires high (Flourishing) or low (Languishing) level on at least one of the following two signs:

1. Regularly cheerful, in good spirits, happy, calm and peaceful, satisfied, and full of life (Positive Affect past 30 days).

2. Feels interested in or satisfied with life (Avowed Interest in Life or Life Satisfaction).

Eudaimonic (Positive Functioning) Well-Being

Criteria: Requires high (Flourishing) or low (Languishing) level on at least 6 or more of the following 11 signs:

3. Holds positive attitudes toward oneself and past life, and is accepting of positive and negative aspects of self (Self-Acceptance).

4. Has positive attitude toward others while acknowledging and accepting people's differences and complexity (Social Acceptance).

5. Shows insight into own potential and sense of development and is open to new and challenging experiences (Personal Growth).

6. Believes that people, social groups, and society have potential and can evolve or grow positively (Social Actualization).

7. Holds goals and beliefs that affirm sense of direction in life and feels that life has a purpose and meaning (Purpose in Life).

8. Feels that one's life is useful to society and the output of own activities is valued by or valuable to others (Social Contribution).

9. Exhibits capability to manage complex environment and can choose or manage and mold environs to suit needs (Environmental Mastery).

10. Interested in society or social life, feels society and culture are intelligible, somewhat logical, predictable, and meaningful (Social Coherence).

11. Exhibits self-direction that is often guided by own, socially accepted and conventional internal standards, and resists unsavory social pressures (Autonomy).

12. Has warm, satisfying, trusting personal relationships and is capable of empathy and intimacy (Positive Relations With Others).

13. Has a sense of belonging to a community and derives comfort and support from community (Social Integration).

Note: Individuals not meeting the languishing or flourishing criteria have moderate mental health. 


\section{Sample}

The Midlife in the United States (MIDUS) is a national probability sample, drawn with random digit dialing procedures, consisting of English-speaking, noninstitutionalized adults, aged 25 to 74, residing in the 48 contiguous states and whose household included at least one telephone. The first stage of the multistage sampling design selected households with equal probability via telephone numbers. Disproportionate stratified sampling was used at the second stage to select one respondent from each household. The sample was stratified by age and sex, with oversampling of men between the ages of 65 and 74. Working nonhousehold (e.g., business) numbers were eliminated by definition, and working numbers that were unsuccessfully contacted 10 times were also eliminated. The MIDUS survey complied with Institutional Review Board standards, and interviewers read a standard informed consent protocol at the beginning of the telephone interview. Adults who agreed to participate were administered a computer-assisted telephone interview lasting $45 \mathrm{~min}$ on average and were then mailed two questionnaire booklets requiring about $1.5 \mathrm{hr}$ on average to complete. All participants were offered $\$ 20$ and a copy of a final study monograph as incentives for participation. With a response rate of $70 \%$ for the telephone phase and a response rate of $87 \%$ for the self-administered questionnaire phase, the overall response rate was $61 \%$ with a sample size of 3,032 respondents, of which 2,485 were White (non-Hispanic) and 339 were Black (non-Hispanic) respondents. Weighted analyses correct for unequal probabilities of household and within-household respondent selection. The sample weight poststratifies the sample to match the proportions of adults according to age, gender, education, marital status, residence (i.e., metropolitan and nonmetropolitan), region (Northeast, Midwest, South, and West), and race based on the October 1995 Current Population Survey. 
1706 